\title{
PIROLISIS LAMBAT CAMPURAN CANGKANG SAWIT DAN PLASTIK DENGAN KATALIS ZEOLIT ALAM
}

\author{
Novan Yuda Wardana ${ }^{1}$, Novi Caroko², Thoharudin ${ }^{3}$ \\ Jurusan Teknik Mesin, Fakultas Teknik, Universitas Muhammadiyah Yogyakarta,2,3) \\ Bantul, Yogyakarta \\ E-mail : thoharudin@gmail.com
}

\begin{abstract}
This research purposes to find out the characteristic of slow pyrolysis of palm kernel shell and plastic derived from waste grocery bags mixtures with the catalyst addition. Palm kernel shell was mixed with plastic in the persentages of $0 \%, 10 \%, 20 \%$ dan 30\%. The mixtures of palm kernel shell and plastic were feeded in the fixedbed pyrolyzer with the natural zeolite as catalyst. Pyrolyzer was heated and controlled in the temperature of $400^{\circ} \mathrm{C}, 450^{\circ} \mathrm{C}$ and $500^{\circ} \mathrm{C}$. Vapor produced by pyrolysis process was condensed by seperated water cooling. Liquid condensation was collected and measured its weight then analyzed by using GCMS to determain the composition of bio-oil formed from this processes. The research results that the higher temperature pyrolyzer the higher conversion of palm kernel shell and plastic mixtures is by reducing char product. The addition of natural zeolit as catalyst affects in the increase of phenol, alkane and alkene compounds with the reduction of acid compounds.
\end{abstract}

Keywords : Slow Pyrolysis, Palm Kernel Shell, Plastic, Natural Zeolite, GCMS.

\section{PENDAHULUAN}

Indonesia merupakan negara penghasil kelapa sawit terbesar dunia setelah Malaysia. Kelapa sawit menjadi salah satu komoditas unggulan Indonesia yang dapat menghasilkan penerimaan negara hingga $\mathrm{Rp} 30,73$ triliun dan divisa negara mencapai $21,3 \%$ pada tahun 2012 (A. Mahbub. 2013) Produksi kelapa sawit Indonesia mengalami peningkatan rata - rata $11,09 \%$ pertahun ( $\mathrm{J}$. Primus, 2015). Dengan demikian, potensi limbah kelapa sawit akan semakin besar seiring dengan peningkatan produksi kelapa sawit yang hingga kini pemanfaatan limbah tersebut belum optimal.

Disamping itu, peningkatan sampah merupakan permasalahan besar yang muncul seiring pertambahan penduduk. Di Yogyakarta ada sekitar 9,98\% sampah plastik dihasilkan dari total sampah yang dibuang di tempat pembuangan akhir sampah (TPA) Piyungan. Sedangkan sampah plastik di Indonesia mencapai 187,2 ton pertahun yang merupakan urutan kedua dunia penghasil sampah plastik setelah Tiongkok (H. Triyoga, 2016). Sementara itu, plastik merupakan polimer hasil pengolahan dari minyak bumi sehingga ditinjau dari segi energi, sampah plastik merupakan sumber energi yang murah dan memiliki nilai kalor yang tinggi yaitu sebesar 42,1 hingga 49,4 $\mathrm{MJ} / \mathrm{kg}$ (B. Kunwar, H.N. Cheng, S.R. Chandrashekaran, and B.K. Sharma, 2016).

Saat ini penggunaan sampah limbah kelapa sawit dan plastik sebagai sumber energi masih terbatas, semisal tidak dapat digunakan langsung sebagai bahan bakar mesin pembakaran dalam. Oleh karena itu perlu teknologi konversi sampah limbah kelapa sawit dan plastik tersebut menjadi bahan bakar cair sehingga lebih fleksibel dalam penggunaan dan mudah dalam penyimpanan. Salah satu teknologi yang kompetitif untuk diaplikasikan adalah pirolisis.

Bio-oil yang diperoleh dari konversi limbah padat melalui proses pirolisis umumnya memiliki tingkat keasaman, kadar air dan kadar oksigen yang tinggi (A. Dewangan, D. Pradhan, and R.K. Singh, 2016) sehingga tidak cocok diaplikasikan langsung manjadi bahan bakar mesin bensin. Oleh karena itu, untuk memperbaiki kualitas bio-oil tersebut dibutuhkan katalis. Katalis yang biasa digunakan antara lain HUSY, Hbeta, Zeolit Y, ZSM-5, zeolit alam, dan 
$\mathrm{Ni} / \mathrm{Al}_{2} \mathrm{O}_{3}$ (C. Muhammad, J.A. Onwudili, 2015). Katalis berbahan dasar zeolit sangat efektif untuk mereduksi kadar oksigen pada bio-oil dan berperan dalam pembentukan ikatan aromatik (D.K. Ojha and R. Vinu, 2015). Selain itu, zeolit juga mampu mereduksi kadar air dalam bio-oil (E. Putun, B.B. Uzun, and A.E. Putun, 2006).

Melihat potensi sumber energi dari sampah yang besar di Indonesia maka sangat menarik untuk dikembangkan menjadi bahan bakar yang fleksibel melalui proses pirolisis. Oleh karena itu penelitian pirolisis limbah sawit dan sampah plastik berkatalis zeolit alam sangat penting untuk dilakukan guna menghasilkan bahan bakar yang berkualitas unggul. Zeolit alam dipilih karena memiliki ketersediaan yang melimpah dengan harga yang murah.

\section{METODE PENELITIAN}

Cangkang sawit merupakan residu padatan yang terproduksi dari sisa pembuatan minyak sawit. Cangkang sawit dipertimbangkan sebagai salah satu sumber energi dari biomassa karena memiliki nilai kalor yang cukup tinggi 21-23 $\mathrm{MJ} / \mathrm{kg}(\mathrm{H}$. Yang et al, 2004). Kandungan ultimate, proximate dan senyawa organik cangkang sawit terlihat pada tabel 1 .

Tabel 1. Sifat Kimia Cangkang Sawit (G. Chang et al,2016)

\begin{tabular}{|c|c|}
\hline \multicolumn{2}{|c|}{ Ultimate Analysis, Wd/\% } \\
\hline $\mathrm{C}$ & 50,73 \\
\hline $\mathrm{H}$ & 5,97 \\
\hline $\mathrm{O}$ & 40,83 \\
\hline $\mathrm{N}$ & 0,36 \\
\hline $\mathrm{S}$ & 0,06 \\
\hline \multicolumn{2}{|c|}{ Proximate Analysis, Wd/\% } \\
\hline Volatiles & 75,21 \\
\hline Fixed carbon & 22,74 \\
\hline Ash & 2,05 \\
\hline \multicolumn{2}{|c|}{ Organic Components. Wd/\% } \\
\hline Cellulose & $20,8-27,7 \%$ \\
\hline Hemicellulose & $21,6-22,3 \%$ \\
\hline Lignin & $44,0-50,7 \%$ \\
\hline
\end{tabular}

Pirolisis dilakukan dengan mencampur cangkang sawit dengan kantong plastik yang dipotong-potong berukuran panjang $3 \mathrm{~cm}$ hingga $7 \mathrm{~cm}$ pada prosentase $0 \%, 10 \%, 20 \%$ dan 30\%. Massa sampel uji pencampuran cangkang sawit dan plastik sebesar $400 \mathrm{~g}$ dimasukkan pada reaktor pirolisis yang berukuran diameter $17 \mathrm{~cm}$ dan tinggi $27,5 \mathrm{~cm}$ tipe fixed bed seperti terlihat pada Gambar 1 . Gas nitrogen dimasukkan ke dalam reaktor digunakan untuk mengusir oksigen yang berada dalam reaktor supaya tidak terjadi pembakaran dengan laju 2 liter/menit. Temperatur pirolisis dikontrol pada $400^{\circ} \mathrm{C}$, $450^{\circ} \mathrm{C}$ dan $500^{\circ} \mathrm{C}$ dengan laju pemanasan rata-rata sebesar $2,5^{\circ} \mathrm{C} /$ menit. Pemanas pirolisis bersumber dari pemanas listrik yang ditempatkan mengelilingi reaktor pirolisis dengan daya 5000 watt.

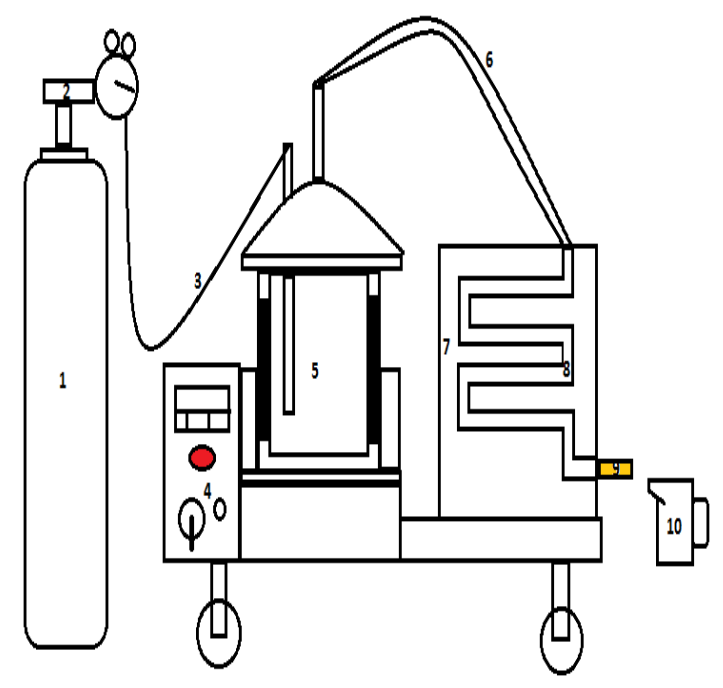

Keterangan :

1.Tabung Nitrogen, 2 Regulator Tekanan, 3.Selang Nitrogen, 4.Pengontrol Suhu, 5.Reaktor Pirolisis, 6.Pipa Penyalur, 7.Tampungan Air Pendingin, 8.Pipa Pendingan, 9.Saluran Keluar Kondensat, 10.Gelas Penampung.

Gambar 1. Skema Pengujian Pirolisis.

Uap hasil pirolisis didinginkan memalui pipa dengan air sebagai fluida pendingin hingga terjadi kondensasi yang ditampung dalam wadah. Hasil kondensasi tersebut kemudian diuji dengan Gas Chromatography Mass Spectrometry (GCMS) untuk mengetahui kandungan senyawa yang terbentuk pada bio-oil. Hasil yang didapatkan dari GCMS kemudian di kelompokkan menurut golongan senyawanya seperti terlihat pada tabel 2 . 
Tabel 2. Penggolongan Sampel Uji Bio-Oil

\begin{tabular}{cc}
\hline Senyawa & Golongan \\
\hline Acetone & Ketone \\
1-Eicosanol & Alcohol \\
Phenol & Phenol \\
Nonadecane & Alkane \\
Cyclopropanebutanoic acid & Acid \\
Squalene & Alkene \\
13-Octadecenal & Aldehyde \\
Cholesta-3,5-diene & Cycloalkene \\
2-Nonadecanone & Ketone \\
1-Heptacosanol & Alcohol \\
Tetratetracontane & Alkane \\
Pentatriacontane & Alkane \\
2,6,10,14,18,22- & \\
Tetracosahexaene & Alkene \\
Tricosanoic acid, methyl ester & Acid \\
Octacosane & Alkane \\
\hline
\end{tabular}

\section{HASIL DAN PEMBAHASAN}

\subsection{Pengaruh Temperatur Pirolisis}

Pirolisis dipengaruhi oleh temperatur akhir pirolisis. Dengan semakin tinggi temperatur akhir pirolisis maka semakin besar konversi pirolisis sehingga sisa arang yang terbentuk semakin rendah. Gambar 2 memperlihatkan hubungan antara temperatur akhir pirolisis terhadap kuantitas produk pirolisis. Terlihat bahwa dengan semakin besar temperatur akhir pirolisis dari $400^{\circ} \mathrm{C}$ hingga $500^{\circ} \mathrm{C}$ sisa arang yang terbentuk semakin rendah seiring dengan penurunan produk cair dan peningkatan produk gas.

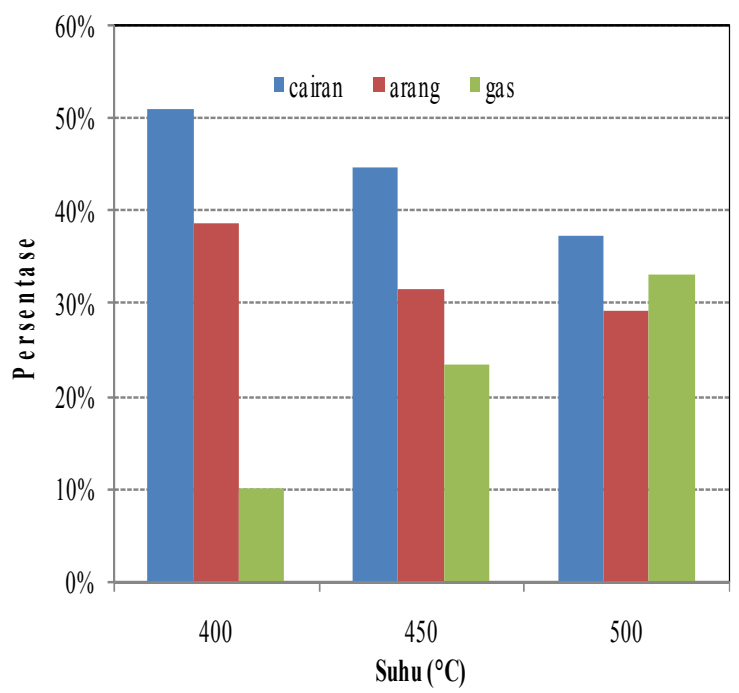

Gambar 2. Pengaruh Temperatur Pirolisis.
Pirolisis berlangsung dengan reaksi endotermis sehingga dengan semakin besar temperatur maka semakin besar pula energi yang digunakan untuk mendekomposisi bahan baku pirolisis. Proses dekomposisi pada temperatur yang tinggi berakibat semakin besarnya laju dekomposisi cangkang sawit dan plastik sehingga arang yang tersisa lebih rendah.

Tingginya temperatur juga berdampak pada turunnya kuantitas cairan disertai dengan tingginya produk gas. Hal ini disebabkan oleh proses secondary cracking yang memecah rantai panjang senyawa organik dan hidrokarbon menjadi rantai yang lebih pendek sehingga tidak dapat dikondensasikan. Secondary cracking berlangsung saat volatil baik dari plastik maupun dari cangkang sawit yang terlepas dan tidak segera terjadi proses pendinginan. Proses ini terjadi di dalam saluran antara reaktor pirolisis dan pipa pendingin. Temperatur tinggi memicu laju reaksi secondary cracking semakin cepat sehingga produk cairan berkurang dengan bertambahnya produk gas.

\subsection{Pengaruh Persentase Plastik}

Cangkang sawit yang dicampur dengan plastik memiliki pengaruh yang signifikan pada penurunan jumlah arang yang berakibat pada besarnya produk cairan dan gas. Akan tetapi dengan semakin besarnya campuran plastik justru berdampak pada peningkatan sisa arang sehingga terjadi penurunan jumlah produk cairan dan gas seperti terlihat pada gambar 3. Selain itu, peningkatan prosentase plastik juga berdampak pada turunnya produk cairan disertai dengan peningkatan produk gas. 


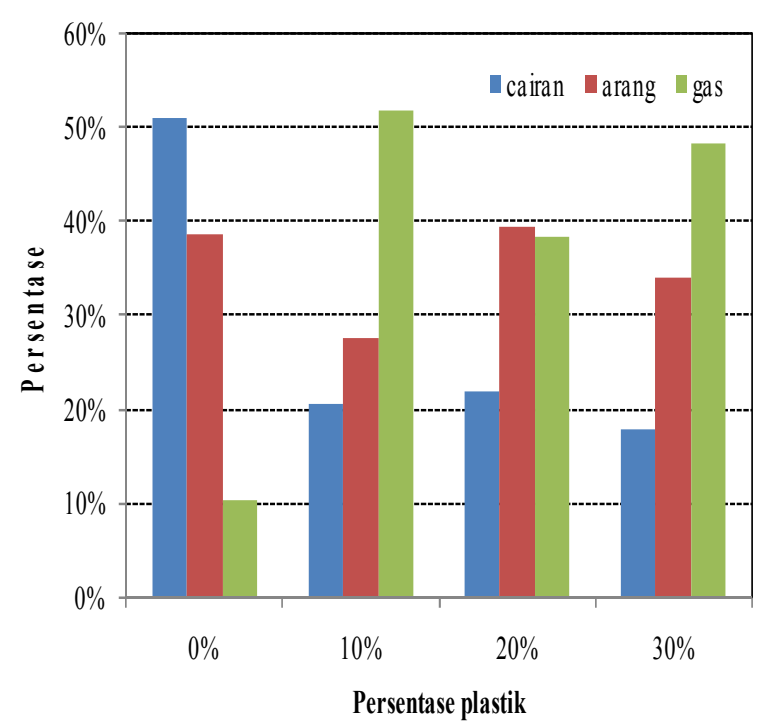

Gambar 3. Pengaruh Prosentase Plastik.

Penurunan produk arang terjadi pada pencampuran cangkang sawit dengan $10 \%$ plastik. Fenomena tersebut dipengaruhi oleh sifat dari plastik yang lebih mudah terdekomposisi daripada cangkang sawit. Kandungan lignin yang tinggi pada cangkang sawit berakibat pada tingginya produk arang karena sifat lignin yang lebih sulit terdekomposisi dibandingkan selulosa dan hemiselulosa (P. Basu, 2010). Dengan penambahan plastik yang mudah terurai tersebut mengakibatkan lingkungan pirolisis kaya akan gas - gas terutama hidrogen. Lingkungan pirolisis yang kaya hidrogen memberikan dampak tingginya laju konversi bahan baku pirolisis sehingga jumlah arang yang tersisa dalam reaktor pirolisis menjadi sedikit (F. Pinto, etc, 2016).

Penambahan jumlah persentase plastik pada pirolisis cangkang sawit lebih dari $10 \%$ berakibat pada tingginya produk arang yang disertai penurunan produk cairan dan gas. Hal ini karena dengan semakin besarnya persentase plastik akan mempersulit volatil terlepas dari batubara mejadi gas. Dalam proses pirolisis bahan baku (cangkang sawit dan plastik) dimasukkan dalam kondisi temperatur ruangan kemudian dipanaskan perlahan hingga pada temperatur yang diinginkan. Pada proses pemanasan tersebut plastik jenis polyethilene (PE) akan meleleh pada temperatur $105^{\circ} \mathrm{C}-130^{\circ} \mathrm{C} \quad(\mathrm{M}$. Paraschiv, etc, 2015). Plastik yang meleleh tersebut akan bersinggungan langsung dengan cangkang sawit dan terbentuk lapisan pada permukaan cangkang sawit yang menghambat volatil keluar. Akibatnya terjadi peningkatan produk arang seiring dengan peningkatan prosentase plastik.

\subsection{Pengaruh Katalis}

Pengaruh katalis zeolit alam terhadap pirolisis campuran cangkang sawit dan plastik terlihat pada gambar 4. Terlihat pada Gambar 4 bahwa dengan penggunaan katalis produk gas meningkat secara signifikan disertai dengan penurunan produk cair. Katalis yang berbahan dasar zeolit bekerja dengan mereduksi komponen oksigen pada bio-oil yang meghasilkan gas - gas $\mathrm{CO}$ dan $\mathrm{CO}_{2}$ melalui reaksi dekarbonilasi ( $\mathrm{Z}$. Guo et al, 2011). Oleh karena itu, terjadi penurunan jumlah cairan dan peningkatan jumlah produk gas secara signifikan.

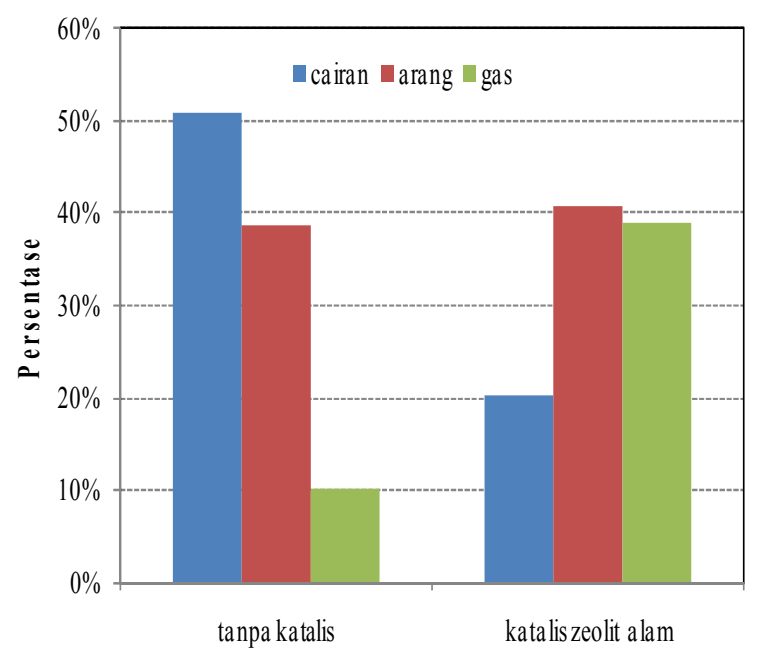

Gambar 4. Pengaruh Katalis.

Efek pada katalis sebagai penurun kadar oksigen pada bio-oil dapat terlihat pada tabel 2. Terlihat pada bio-oil tanpa katalis, komponen terbesar penyusunnya di dominasi oleh phenol dan acid sebesar $42,72 \%$ dan $55,11 \%$. Sementara itu, pirolisis dengan melibatkan zeolit alam sebagai katalis berdampak pada tingginya golongan phenol, alkane, dan alkene yaitu sebesar $62,52 \%$, $20,47 \%$ dan $6,85 \%$. 
Penurunan golongan acid / asam dan peningkatan golongan alkane dan alkene tersebut karena adanya reaksi dekarbonilasi yang memecah ikatan oksigen pada golongan acid sehingga menjadi rantai alkane dan alkene seperti terlihat pada gambar 5 . Sementara itu zeolit juga sebagai katalis terbentuknya gugusan aromatik dengan mengikat gas - gas seperti etilene, etane, propilene dan propane melalui reaksi aromatisasi hingga membentuk gugusan aromatik. Oleh karena itu, komponen phenol meningkat dengan pirolisis melibatkan zeolit alam sebagai katalis. Phenol merupakan senyawa aromatik yang memiliki rantai $\mathrm{OH}$.

Tabel 3. Golongan Bio-Oil Pirolisis

\begin{tabular}{lcc}
\hline \multicolumn{1}{c}{ Golongan } & $\begin{array}{c}\text { Tanpa } \\
\text { Katalis }\end{array}$ & $\begin{array}{c}\text { Dengan } \\
\text { Katalis }\end{array}$ \\
\hline Phenol & $42,72 \%$ & $62,52 \%$ \\
Alkane & $0,00 \%$ & $20,47 \%$ \\
Alkene & $0,00 \%$ & $6,85 \%$ \\
Alcohol & $0,00 \%$ & $1,61 \%$ \\
Furan & $0,00 \%$ & $2,04 \%$ \\
Ketone & $0,65 \%$ & $2,29 \%$ \\
Aldehyde & $0,00 \%$ & $0,82 \%$ \\
Cycloalkane & $0,00 \%$ & $0,28 \%$ \\
Cycloalkene & $0,00 \%$ & $0,52 \%$ \\
Acid & $55,11 \%$ & $2,61 \%$ \\
Aromatic & $0,65 \%$ & $0,00 \%$ \\
Toluene & $0,55 \%$ & $0,00 \%$ \\
Acetat & $0,31 \%$ & $0,00 \%$ \\
\hline
\end{tabular}<smiles></smiles><smiles>[R]CC([2H])([2H])C(=O)OO</smiles>

Gambar 5. Mekanisme Pembentukan Alkane dari Acid Melalui Reaksi Dekarbonilasi.

\section{KESIMPULAN}

Penelitian tentang pirolisis lambat campuran cangkang sawit dan plastik telah dilakukan dan memperlihatkan pengaruh temperatur, prosentase plastik dan pengaruh katalis. Secara umum terlihat pengaruh dari temperatur terlihat pada penurunan sisa arang dengan tingginya temperatur disertai dengan peningkatan produk gas dan penurunan produk cair. Penambahan plastik pada proses pirolisis juga berdampak pada kuantitas produk.

Katalis zeolit alam berfungsi dengan baik untuk mereduksi kandungan oksigen pada cairan bio-oil. Terbukti dengan penambahan katalis berdampak pada turunnya golongan acid/asam dan naiknya golongan alkane dan alkene.

\section{DAFTAR PUSTAKA}

A. Dewangan, D. Pradhan, and R.K. Singh, "Co-Pyrolysis of Sugarcane Bagasse and Low-Density Polyethylene: Influence of Plastic on Pyrolysis Product Yield," Fuel, vol. 185, pp. 508-516, 2016.

A. Mahbub. Perkebunan Kelapa Sawit Diklaim Sesuai Moratorium. [Online]. https://bisnis.tempo.co/read/news/2013 /04/23/090475197/perkebunan-kelapasawit-diklaim-sesuai-moratorium, 2013.

B. Kunwar, H.N. Cheng, S.R. Chandrashekaran, and B.K. Sharma, "Plastics to Fuel: A Review," Renewable and Sustainable Energy Reviews, vol. 54, pp. 421-428, 2016.

C. Muhammad, J.A. Onwudili, and P.T. Williams, "Catalystic Pyrolysis of Waste Plastic from Electrical and Electronic Equipment," Journal of Analytical and Applied Pyrolysis, vol. 113, pp. 332-339, 2015.

D. K. Ojha and R. Vinu, "Resource Recovery Via Catalytic Fast Pyrolysis of Polystyrene Using Zeolites," Journal of Analytical and Applied Pyrolysis, vol. 133, pp. 349-359, 2015. 
E. Putun, B.B. Uzun, and A.E. Putun, "Fixedbed Catalytic Pyrolysis of Cotton-Seed Cake: Effects of Pyrolysis Temperature, Natural Zeolite Content and Sweeping Gas Flow Rate," Bioresource Technology, vol. 97, pp. 701-710, 2006.

F. Pinto, M. Miranda, and P. Costa, "Production of Liquid Hydrocarbons from Rice Crop Wastes Mixtures by Co-Pyrolysis and Co-Hydropyrolysis," Fuel, vol. 174, pp. 153-163, 2016.

G. Chang et al., "The Lignin Pyrolysis Composition and Pyrolysis Products of Palm Kernel Shell, Wheat Straw, and Pine Sawdust," Energy Conversion and Management, vol. 124, pp. 587-597, 2016.

H. Triyoga. detik.com. [Online]. http://news.detik.com/berita/3137410/i ndonesia-peringkat-ke-2-penghasilsampah-ke-laut, 2016.

H. Yang et al., "Thermogravimetric AnalysisFourier Transform Infrared Analysis of Palm Oil Waste Pyrolysis," Energy \& Fuel, vol. 18, pp. 1814-1821, 2004.

J. Primus. Masih Banyak Tantangan di Industri Kelapa Sawit. [Online]. http://bisniskeuangan.kompas.com/read /2015/02/10/183444926/Masih.Banyak .Tantangan.di.Industri.Kelapa.Sawit, 2015.

M. Paraschiv, R. Kuncser, M. Tazerout, and T. Prisecaru, "New Energy Value Chain Through Pyrolysis of Hospital Plastic Waste," Applied Thermal Engineering, vol. 87, pp. 424-433, 2015.

P. Basu, Biomass Gasifcation and Pyrolysis Practical Design and Theory. Oxford: Elsevier Inc., 2010.

Z. Guo et al., "Catalytic Cracking Characteristics of Bio-oil Molecular Distillation Fraction," in World Renewable Energy Congress, Linkoping, 2011, pp. 552-559. 